\title{
Emulsion Liquid Membrane for Cadmium Removal: Determination of Liquid Membrane Components
}

\author{
Adhi Kusumastuti, ${ }^{1 *}$ Nur Qudus, ${ }^{1}$ Samsudin Anis ${ }^{1}$ and Abdul Latif Ahmad ${ }^{2}$ \\ ${ }^{1}$ Faculty of Engineering Universitas Negeri Semarang, Kampus UNNES Sekaran, \\ Semarang 50229, Indonesia \\ ${ }^{2}$ School of Chemical Engineering Universiti Sains Malaysia, Engineering Campus, \\ 14300 Nibong Tebal, Pulau Pinang, Malaysia
}

*Corresponding author: adhi_kusumastuti@mail.unnes.ac.id

Published online: 30 July 2018

To cite this article: Kusumastuti, A. et al. (2018). Emulsion liquid membrane for cadmium removal: Determination of liquid membrane components. J. Phys. Sci., 29(Supp. 2), 227242, https://doi.org/10.21315/jps2018.29.s2.18

To link to this article: https://doi.org/10.21315/jps2018.29.s2.18

\begin{abstract}
Removal of cadmium is very important as it is one of several harmful heavy metals commonly found in textile wastewater. This study focused on determination of emulsion liquid membrane (ELM) components for cadmium removal. Carrier, diluent and stripping selection was done by contacting feed phase (150 ppm cadmium) with organic solution at ratio of 1:1. Both solutions were mixed at $500 \mathrm{rpm}$ for 24 h using magnetic stirrer, then the samples were allowed to settle and separate. The results of the study showed that in comparison with acid solution, basic solution containing trioctylamine (TOA), kerosene and $\mathrm{NH}_{3}$ as the carrier, diluent and stripping agent, respectively provided the best performance for cadmium removal using ELM. In addition, the ordering of the extraction in terms of magnitude for the diluents was highly correlated with the polarity, solubility and viscosity. Low polarity and viscosity, and high solubility of the diluent are preferred.
\end{abstract}

Keywords: Emulsion liquid membrane, liquid membrane components, cadmium, extraction, ELM

\section{INTRODUCTION}

Textile is one of the major industries in Indonesia. Textile industry plays an important role in the economy of Indonesia, growing linearly since 2010. It is the third biggest export after palm oil and rubber products. There are many sectors in 
textile processing, i.e., fibre preparation, spinning, fabric making, colouring and finishing. The last two processes involve the use of huge amount of water. Textile finishing processes involve bleaching, dyeing, printing and stiffening of various processing stages (fibre, yarn, fabric, knits and finished items). ${ }^{1}$ The finishing process is aimed to improve the look, performance and acceptability of the finished textile products to meet the requirements of the following process. Colouring process can be done through dyeing and printing. Both processes apply many types of textile dyes such as anionic which are direct, acid and reactive dyes, cationic which are basic dyes, non-ionic which are disperse dyes, azo, diazo, anthroquinone based and metal complex dyes. ${ }^{2}$ The wastewater from colouring process compose of metals, salt, surfactants, organic processing assistants, cationic materials, colour, biological oxygen demand (BOD), chemical oxygen demand (COD), sulphide, acidity/alkalinity, spent solvents, suspended solids, urea, solvents, colour, heat and foam. ${ }^{1}$ The commonly available metals in textile wastewater are $\mathrm{Pb}, \mathrm{Fe}, \mathrm{Cu}, \mathrm{Cd}$, $\mathrm{Zn}, \mathrm{Ni}$ and $\mathrm{Cr} .{ }^{3,4}$

Batik is an industry that involves textile printing and dyeing processes. Indonesia has areas operating batik business. The economy of certain areas, such as Pekalongan, mainly depend on batik industry since there were about 1,115 batik home operators in $2011 .{ }^{5}$ Printing and dyeing processes consume about 16 and 3001 water per $\mathrm{kg}$ product, respectively. In Pekalongan, about $4500 \mathrm{~m}^{3}$ textile wastewater is released daily. ${ }^{1}$ The capacity of wastewater treatment installation is only about $40 \%$. Considering the harmful effects of the wastewater, a proper action is urgently needed to overcome the problems.

There are many methods offered to solve textile industrial wastewater problem. Some research in textile wastewater treatments have been done by coagulation, adsorption, membrane separation and extraction. ${ }^{6-14}$ Those conventional technologies have their own advantages and disadvantages. Emulsion liquid membrane (ELM) as an alternative of solvent extraction provides advantages of combining extraction and stripping process in a single step, thus minimising the equipment as well as processing time. This method also effectively removes lowconcentration contaminants usually available in textile wastewater.

The basic process of ELM is the use of a three-phase dispersion system. In this system, primary emulsion that consists of membrane and stripping phase is dispersed in the feed or effluent phase, which is the phase to be treated. Carrier as an organic soluble extractant is used for metal separation even in a very low concentration. The metal and carrier form a complex that is soluble in the membrane phase. Subsequently, this complex will permeate through the membranes from the outer to the inner interface. At the inner interface, the complex decomposes through 
reversal of the equilibrium reaction and the metal ion is released into the internal phase and the regenerated free carrier diffuses back into the membrane phase.

Although ELM process offers several advantages for various industrial wastewater recoveries including heavy metals, the method needs to be improved to overcome some technical barriers in its application, especially the removal of lowconcentration cadmium in the wastewater. The successful application of this method is not only dependent on the selection of suitable emulsification process but also the emulsion formulation in accordance to the solute which is to be recovered. This is obviously related to the emulsion stability that still remains a great challenge for ELM application at industrial scale. It was reported that generally ELM processes suffer emulsion instability of about $8 \%$ on average in terms of membrane breakage and emulsion swelling of about $35 \%$ on average. ${ }^{15-20}$ These figures are interesting when considering the ELM tolerance for membrane breakage and emulsion swelling of $0.1 \%$ and $10 \%$, respectively. ${ }^{21,22}$

In order to obtain the liquid membrane with best performance, a detailed study was done to select potential carriers, diluent and stripping solutions which are suitable for cadmium recovery under batch ELM process. The efficiency of extraction process was governed by emulsion formulation including types of carrier. Three parameters namely carrier, stripper and diluent were investigated to screen the most suitable carrier, stripping solution and diluent on extraction efficiency. Several potential carriers and diluents were compared toward their cadmium extraction capacity under emulsion liquid membrane system. Carrier and diluent selections were considered based on their performance in extracting cadmium, with parameter of extraction efficiency.

Carriers were selected based on their capacity to recover cadmium. The suitable carrier must have high tendency in forming complex with cadmium ion. Carrier screening experiment was carried out using two types of carrier, i.e., trioctylamine (TOA) and di-(2-ethylhexyl) phosphoric acid (D2EHPA) which were run under various concentrations. Three types of organic solutions, i.e., kerosene, n-heptane and oxylene were tested. The determination of liquid membrane components was carried out by employing cadmium solvent extraction process, each for extraction and stripping process. 


\section{EXPERIMENTAL}

\subsection{Materials}

The non-ionic surfactant of sorbitan monooleate which is commercially known as Span 80 was used as emulsion stabiliser. Kerosene, oxylene (>99\%) and n-heptane $(>99 \%)$ were used as a diluent. Ammonia solution (25\%), nitric acid (65\%) and acetic acid (96\%) were used as internal phase. TOA (>95\%) and D2EHPA (95\%) were used as carrier. Cadmium chloride $(99.99 \%)$ was used in the external feed phase. Deionised water was used to prepare all aqueous solutions. The research employed reagents of analytical grade. Span 80, oxylene, n-heptane, ammonia, nitric acid, acetic acid, TOA and D2EHPA were purchased from Merck. Lowodour kerosene and cadmium chloride were obtained from Sigma Aldrich.

\subsection{Procedures}

Carrier/extractant and diluent selection was done by contacting feed phase (cadmium solution) with organic solution at ratio of 1:1 as given by some studies on cadmium removal using solvent extraction process. ${ }^{23-29}$ Cadmium concentration in feed phase was kept constant at $150 \mathrm{ppm}$. The organic solution consisted of carrier and diluent at various concentrations. Both solutions were mixed at $500 \mathrm{rpm}$ for $24 \mathrm{~h}$ using magnetic stirrer, then the samples were allowed to settle and separate. The concentration of cadmium in the feed phase was measured using atomic absorption spectrophotometer (AAS) at wavelength $228.5 \mathrm{~nm}$. The cadmium concentration in loaded organic phase was obtained by mass balance. The obtained value was then used to calculate extraction efficiency as given in the following equation:

$$
\text { Extraction efficiency }=\frac{C_{A, I I}^{0}-C_{A, I I I}}{C_{A, I I I}^{0}} \times 100 \%
$$

Complete parameters and conditions are presented in Table 1.

Screening for type of stripping solution was done by contacting aqueous phase and organic phase using magnetic stirrer. The aqueous phase consisted of stripping solution either $\mathrm{NH}_{3} \mathrm{HNO}_{3}$ or $\mathrm{CH}_{3} \mathrm{COOH}$ at fixed concentration of $0.1 \mathrm{M}$. While the organic phase contained $4 \mathrm{wt} \%$ loaded TOA and $96 \mathrm{wt} \%$ kerosene. Both of aqueous and loaded organic phases were contacted in the equal volume for $24 \mathrm{~h}$. Afterwards, the samples were allowed to settle and separate. Cadmium concentration in aqueous phase was measured by AAS while cadmium concentration in organic phase was calculated by mass balance. Extraction and stripping efficiency were calculated by Equation 1. 
Table 1: Parameters and conditions for screening of emulsion component.

\begin{tabular}{|c|c|c|}
\hline \multirow{2}{*}{ Component } & \multicolumn{2}{|c|}{ Condition } \\
\hline & Extraction & Stripping \\
\hline Type of carrier & D2EHPA and TOA & TOA \\
\hline Carrier concentration & $\begin{array}{l}4-16 \mathrm{wt} \% \text { (D2EHPA) } \\
1-6 \mathrm{wt} \%\end{array}$ & $4 \mathrm{wt} \%$ \\
\hline Type of diluent & Kerosene, n-heptane, oxylene & Kerosene \\
\hline Type of internal phase & - & $\mathrm{NH}_{3}, \mathrm{HNO}_{3}, \mathrm{CH}_{3} \mathrm{COOH}$ \\
\hline Feed solution and concentration & $150 \mathrm{ppm} \mathrm{Cd}$ in $0.1 \mathrm{M} \mathrm{HCl}$ & Loaded organic solution \\
\hline Treat ratio & $1: 1$ & $1: 1$ \\
\hline Stirring rate and time & $500 \mathrm{rpm}$ for $24 \mathrm{~h}$ & $500 \mathrm{rpm}$ for $24 \mathrm{~h}$ \\
\hline
\end{tabular}

\section{RESULTS AND DISCUSSION}

\subsection{Carrier Screening}

Theoretically, higher carrier concentration results in higher extraction capacity. However, instead of using excessive concentration of carrier unnecessarily, optimum amounts are required to ensure the economic feasibility. Based on these points of view, a series of experiments had been conducted to determine the most suitable carrier for liquid membrane formulation. The examined carriers were divided into acidic and basic types.

\subsubsection{Acidic extractant}

D2EHPA was first examined as a carrier for cadmium extraction. For better understanding of the behaviour of the carrier, the effect of carrier concentration on the cadmium efficiency was investigated using solvent extraction experiments. The experimental results are presented in Figure 1. The bar chart given in the figure represents the cadmium extraction efficiency provided from contacting equal volume of feed and organic solutions for $24 \mathrm{~h}$ at $500 \mathrm{rpm}$. Feed solution was $150 \mathrm{ppm}$ cadmium in $0.1 \mathrm{M} \mathrm{HCl}$ whilst organic solution was composed of D2EHPA and kerosene as an extractant and diluent, respectively. It can be seen from Figure 1 that the extraction efficiency was highly affected by carrier concentration. Only about 35\% cadmium was extracted using $4 \mathrm{wt} \%$ D2EHPA. The extraction efficiency enhanced significantly from $4 \mathrm{wt} \%$ to $12 \mathrm{wt} \%$ of carrier concentration. The result showed that carrier concentration of $12 \mathrm{wt} \%$ enhanced the extraction efficiency to about $92 \%$. Expecting higher extraction efficiency, 
carrier concentration was further increased $16 \mathrm{wt} \%$, but the increase of extraction efficiency was not significant. At $16 \mathrm{wt} \%$, the system should reach about the same efficiency. This means that D2EHPA has an optimum concentration to extract cadmium from feed solution under the condition investigated. Significant increase of extraction efficiency was within $4 \mathrm{wt} \%$ to $12 \mathrm{wt} \%$.

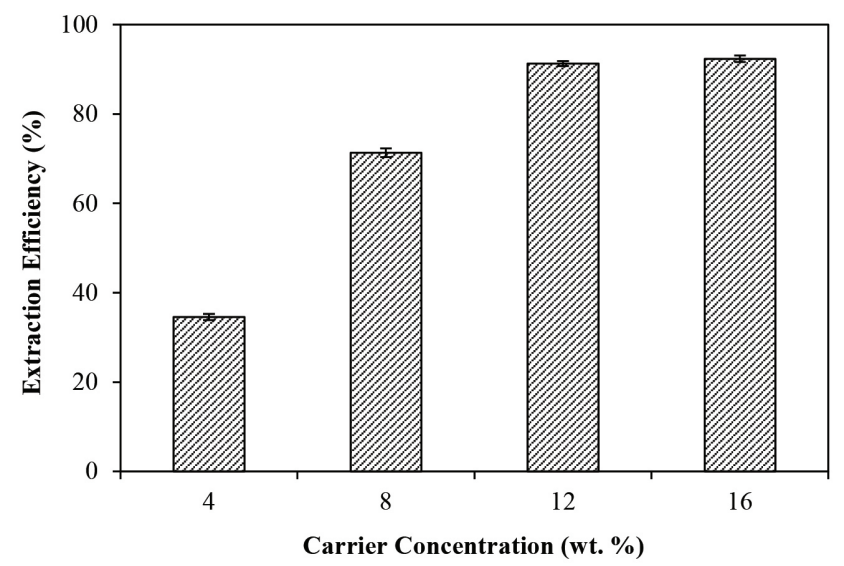

Figure 1: Effect of D2EHPA concentration on extraction efficiency.

The distribution coefficient $\left(\mathrm{K}_{\mathrm{D}}\right)$ of cadmium prepared by D2EHPA concentration could be obtained from the plot of $\log (\mathrm{D} 2 \mathrm{EHPA})$ versus $\log \mathrm{K}_{\mathrm{D}}$ slope of the line is equal to the number of carrier molecules associated with a metal atom in the extracted species. It was found in Figure 2 that the obtained slope was almost equal to 2, indicating that one mole of cadmium would react with two moles of D2EHPA as mentioned by Basualto et al..$^{30}$ Based on these result, the distribution coefficient of various D2EHPA concentration was evaluated by the following equation:

$$
\mathrm{K}_{\mathrm{D}}=\mathrm{K}_{D}=\frac{C_{A, I I}}{C_{A, I I I}}
$$

$\mathrm{K}_{\mathrm{D}}$ shows the distribution coefficient, $C_{A, I I}$ is organic solution $\left(\mathrm{mg}^{1^{-1}}\right)$, and $\mathrm{C}_{\mathrm{A}, \mathrm{III}}$ is cadmium-complex concentration in is cadmium concentration in feed phase ( $\mathrm{mg} \mathrm{l}^{-1}$ ). Based on the obtained slope value, cadmium reacted with D2EHPA following the reaction as follows:

$$
\mathrm{CdCl}_{2-}{ }_{2-}+2(H R)_{2} \leftrightarrow\left(\mathrm{CdCl}_{4} \mathrm{R}_{2}\right) \cdot(\mathrm{HR})_{2}+2 \mathrm{H}^{+}
$$




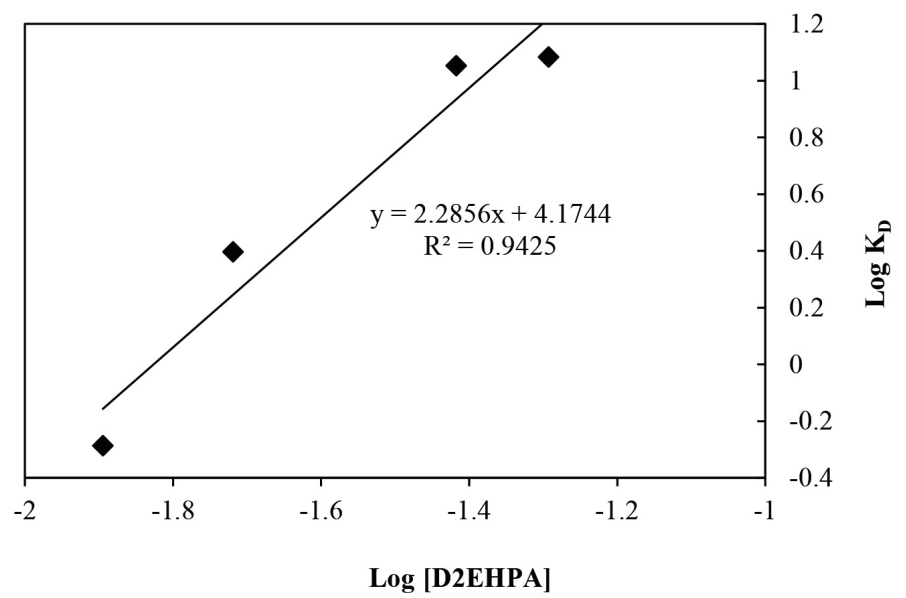

Figure 2: Relationship between D2EHPA concentrations to distribution coefficient.

It should be noted that cadmium in feed solution was available at $150 \mathrm{ppm}$ which is equivalent to 0.0000205 moles. In the meantime, the D2EHPA concentrations employed were $4 \mathrm{wt} \%, 8 \mathrm{wt} \%, 12 \mathrm{wt} \%$ and $16 \mathrm{wt} \%$ which are equivalent to $0.000382,0.00077,0.001147$ and 0.001537 moles, respectively. Thus, theoretically all the D2EHPA concentrations examined are enough to extract cadmium from feed solution. However, the diffusion of cadmium from aqueous into organic phases is limited due to the existence of mass transfer resistance in the interface of aqueous and organic phases. ${ }^{31}$ Thus, higher carrier concentration is preferred as it has higher amount of free D2EHPA for reaction as evidenced by Equation 3. This is consistent with the results obtained above that better cadmium extraction efficiencies were obtained at D2EHPA concentrations of above $8 \mathrm{wt} \%$. Similar observation was also found in previous studies that much more amount of extractant is needed to obtain high extraction efficiency using D2EHPA. ${ }^{25,26}$ They found that when toluene was used as the organic phase, high concentration of 0.1 M D2EHPA (equivalent with $3.7 \mathrm{wt} \%$ ) was needed to obtain $82 \%$ extraction efficiency from $5 \mathrm{ppm}$ cadmium in aqueous solution. ${ }^{26}$ In another case, when kerosene and mixture of $1 \%$ isodecanol with D2EHPA were used as the diluent and extractant respectively, the minimum concentration of $0.15 \mathrm{M}$ D2EHPA (equivalent with $6 \mathrm{wt} \%$ ) was required to achieve $78 \%$ extraction efficiency from $0.00445 \mathrm{M}(500 \mathrm{ppm})$ cadmium in aqueous solution. ${ }^{26}$

\subsubsection{Basic extractant}

Basic extractant has been known as a promising agent in metal extraction. TOA as a type of basic extractant was chosen and tested in order to study its capability for 
cadmium extraction. In order to obtain a clear interpretation of the effect of basic extractant concentration on cadmium extraction efficiency, the solvent extraction experiment was conducted at various TOA concentrations of $1 \mathrm{wt} \%, 2 \mathrm{wt} \%, 4 \mathrm{wt} \%$ and $6 \mathrm{wt} \%$. Feed solution was $150 \mathrm{ppm}$ cadmium in $0.1 \mathrm{M} \mathrm{HCl}$ whilst organic solution is composed of TOA and kerosene as extractant and diluent, respectively. The result is plotted in Figure 3. It can be seen from the figure that as in the case of D2EHPA, the cadmium extraction efficiency using TOA was also highly affected by the extractant concentration. Very limited amount of cadmium could be extracted using TOA concentration of $1 \mathrm{wt} \%$. However, extraction efficiency improved progressively when the extractant concentration was raised from $1 \mathrm{wt} \%$ to $4 \mathrm{wt} \%$. Further increase of extractant concentration beyond $4 \mathrm{wt} \%$ resulted in almost the same extraction efficiency, in which more than $90 \%$ of cadmium was extracted using $4 \mathrm{wt} \%$ and $6 \mathrm{wt} \%$ of extractant concentration, respectively. This result indicates that it is more than enough to remove cadmium from feed phase by utilising $4 \mathrm{wt} \%$ of extractant concentration. Previous studies pointed out that one of the best extractant to remove cadmium by solvent extraction was TOA in kerosene. ${ }^{32,33}$ Cadmium can form anionic chloro complexes in chloride solutions and they could be separated from the organic phase by contacting with organic anion exchanger such as protonated TOA. It can be confirmed that below $10 \%$ of TOA was enough to extract cadmium with efficiency of about $90 \%{ }^{33}$

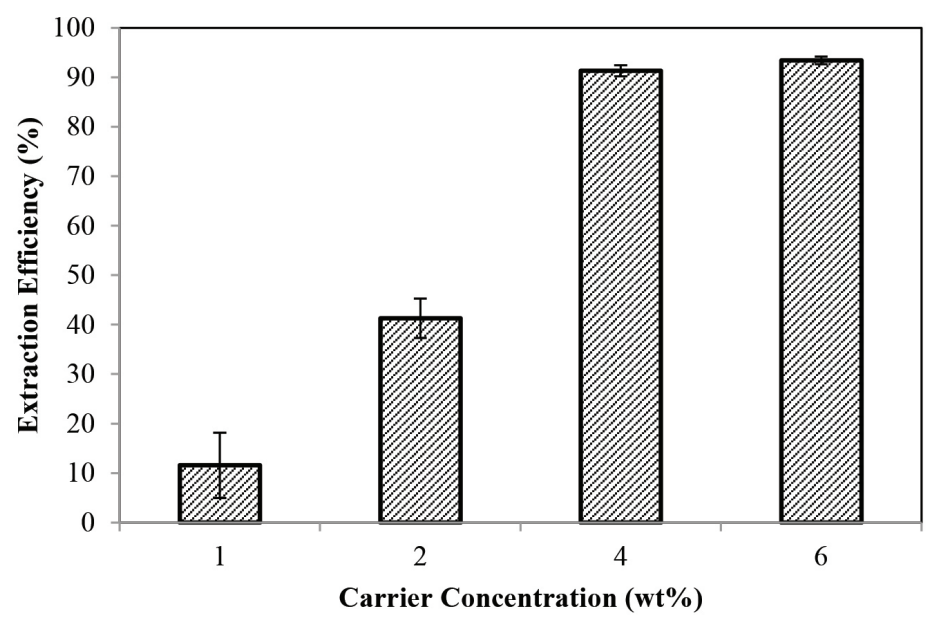

Figure 3: Effect of TOA concentration on extraction efficiency.

The distribution coefficient of cadmium extraction under different TOA concentrations is determined in Figure 4 through the plot of $\log$ (TOA) versus log $\mathrm{K}_{\mathrm{D}}$. It could be observed that the obtained slope was about 2, indicating that one mole of cadmium would react with two moles of TOA. Since $4 \mathrm{wt} \%$ of extractant 
concentration has 0.000346 mole of TOA, it is more than enough to extract 0.0000205 mole of cadmium from $150 \mathrm{ppm}$ cadmium contained in feed phase by considering mass transfer resistance in the interface of aqueous and organic phases. Therefore, $4 \mathrm{wt} \%$ of TOA is sufficient.

Based on the obtained slope value, the extraction of cadmium using TOA as extractant was given by the following equation:

$$
2 \mathrm{H}^{+}+\mathrm{CdCl}_{2-}^{4}+2 \mathrm{R}_{3} \mathrm{~N} \leftrightarrow\left(\mathrm{R}_{3} \mathrm{NH}\right)_{2} \mathrm{CdCl}_{4}
$$

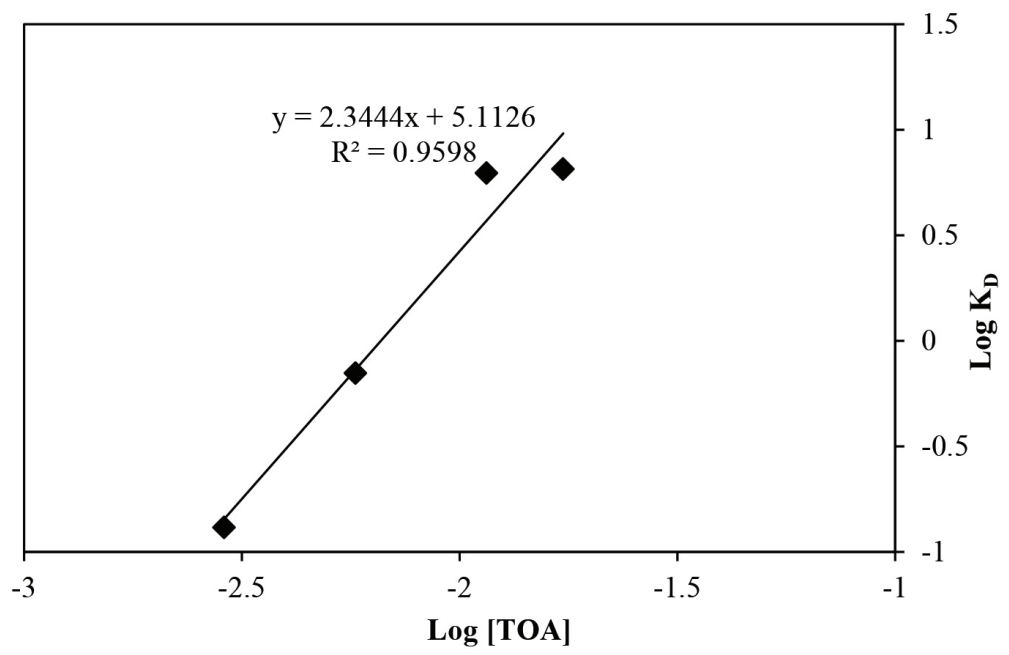

Figure 4: Relationship between TOA concentrations to distribution coefficient.

Compared to D2EHPA, TOA has better efficiency in extracting cadmium on the same weight basis. Hence, TOA will be used as the extractant in the subsequent studies. Moreover, this finding is important since in ELM processes the extractant or carrier is the most expensive material for emulsion composition. Therefore, it is expected that by minimising the amount of carrier, the overall ELM processes become economically feasible.

\subsection{Diluent Screening}

Several types of diluent, namely n-heptane, oxylene and kerosene were tested for dilution of TOA and used for extraction of $150 \mathrm{ppm}$ cadmium in aqueous feed solution. The TOA was completely soluble in all tested diluents. In this study, TOA concentration was fixed at $4 \mathrm{wt} \%$. The cadmium extraction was performed 
by contacting equal volume of feed and organic solutions for $24 \mathrm{~h}$ at $500 \mathrm{rpm}$. Extraction efficiency generated by these three diluents is presented in Figure 5.

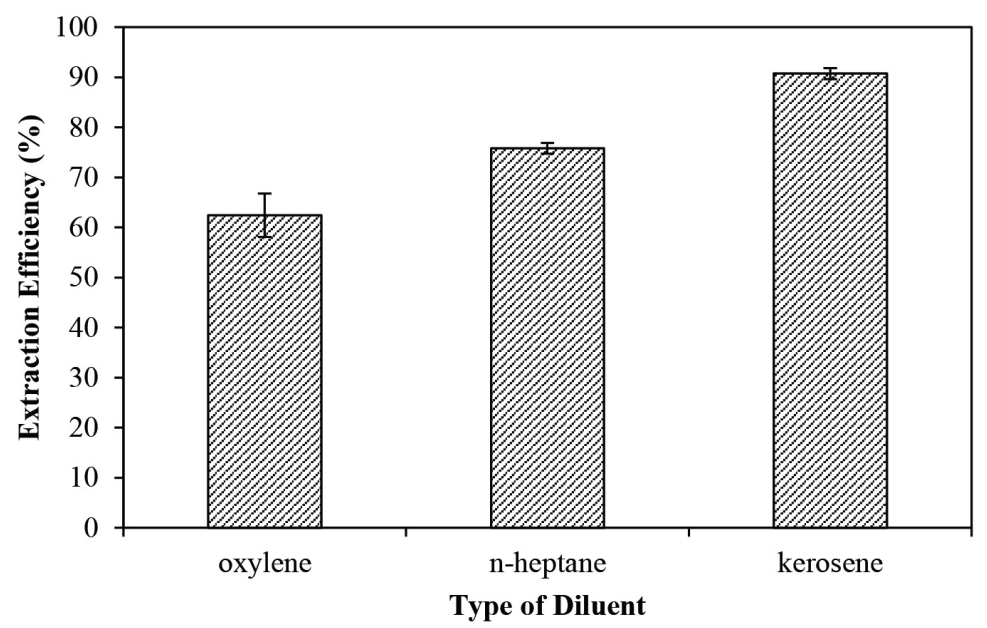

Figure 5: Effect of type of diluents on extraction efficiency.

It can be seen from the figure that the highest extraction efficiency of about $91 \%$ was obtained for kerosene, whereas organic solution contained oxylene as the diluent generated the lowest extraction efficiency of about $62 \%$. This result gives an impression of the sequence of extraction ability by different diluents as follows: kerosene $>\mathrm{n}$-heptane $>$ oxylene. Kerosene and n-heptane as aliphatics diluents are generally preferred than oxylene as aromatic diluents because of its low solubility in water. ${ }^{34,35}$ Moreover, the ordering of the extraction in terms of magnitude for the diluents is also highly correlated with the polarity or dielectric constant of the diluents. The value of dielectric constant is 1.8 for kerosene, 1.9 for $n$-heptane, and 2.6 for oxylene. An increase in polarity or dielectric constant of the diluent caused a reduction in extraction efficiency. ${ }^{36,37}$

The evaluation result is given in Table 2. As shown, kerosene as the diluent in organic solution has higher distribution coefficient due to the high cadmium extraction efficiency. Since kerosene provides better extraction performance and distribution coefficient, it was selected as the suitable diluent in the subsequent studies. In addition, kerosene has high boiling point, high solubility of extractant, low toxicity, relatively low viscosity, and it is commercially available with low price, making it more preferred as the diluent. Later, for ELM application, these properties might give better stability, especially in emulsification process aided by a sonicator. Less viscous solution undergoes easier cavitation to form the emulsion, resulting in better emulsion stability. ${ }^{38}$ The application of demulsification in the 
end of ELM process can minimise the side effect of using this diluent since the used diluent can be recycled.

Table 2: Distribution coefficient of different diluents.

\begin{tabular}{ll}
\hline Diluent & $\mathrm{K}_{\mathrm{D}}$ \\
\hline Oxylene & 2.99 \\
n-Heptane & 5.21 \\
Kerosene & 15.17 \\
\hline
\end{tabular}

\subsection{Stripping Agent Screening}

Another component of liquid membrane is the stripping agent. The stripping agent must be able to strip off the complex of extractant/carrier and metal ion. Using TOA as selected carrier and kerosene as selected diluent for cadmium extraction, study was continued in screening the suitable stripping agent. An acid was employed as stripping solution namely nitric acid $\left(\mathrm{HNO}_{3}\right)$, while for the basic solution, ammonia $\left(\mathrm{NH}_{3}\right)$ and acetic acid $\left(\mathrm{CH}_{3} \mathrm{COOH}\right)$ were chosen.

The experiments were performed by contacting the aqueous and loaded organic phases in the equal volume for $24 \mathrm{~h}$. The aqueous phase consisted of stripping solution either $\mathrm{NH}_{3} \mathrm{HNO}_{3}$ or $\mathrm{CH}_{3} \mathrm{COOH}$ at a fixed concentration of $0.1 \mathrm{M}$, while the organic phase contained $96 \mathrm{wt} \%$ kerosene and $4 \mathrm{wt} \%$ loaded TOA obtained from previous diluent screening experiment. Figure 6 shows the capability of $\mathrm{NH}_{3}$, $\mathrm{HNO}_{3}$ and $\mathrm{CH}_{3} \mathrm{COOH}$ to strip cadmium from loaded organic phase. It was found that $\mathrm{NH}_{3}$ solution gave the highest extraction efficiency whilst the system using $\mathrm{HNO}_{3}$ gave the lowest. This shows that under the investigated condition, basic solution is more suitable to strip the cadmium from organic phase containing TOA as the extractant compared to acid solution. This condition is possible because in the stripping reaction, cadmium ion was released from the complex by the $\mathrm{OH}^{-}$ anion contained in the basic stripping solution. ${ }^{39}$ On the contrary, the use of acid stripping agents formed a species of $\mathrm{H}_{2} \mathrm{CdCl}_{4}$ which is not completely ionised, thus reducing the amount of $\mathrm{H}^{+}$in the stripping solution. Consequently, further stripping reaction would decrease due to the less availability of proton. ${ }^{40}$ 


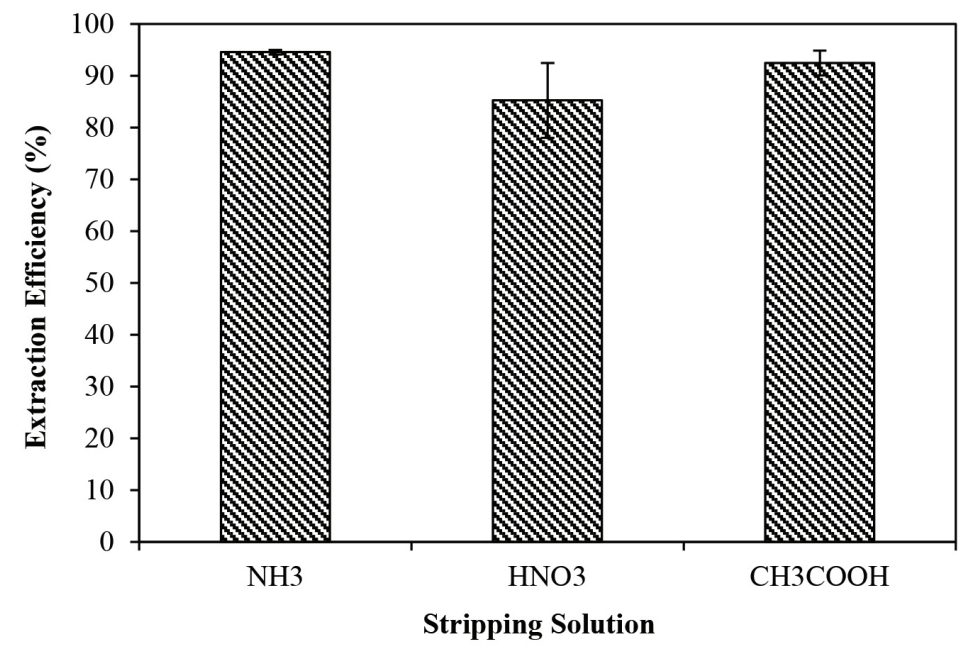

Figure 6: Extraction efficiency for different types of stripping solution.

Based on the result above, the distribution coefficient of different types of stripping solution was also evaluated. The evaluation result is given in Table 3. As shown, $\mathrm{NH}_{3}$ as the stripping agent has higher distribution coefficient. This is not surprising as it provides high cadmium extraction efficiency. Since $\mathrm{NH}_{3}$ provides better extraction performance and distribution coefficient, it was chosen as the suitable internal phase solution for further study in ELM system.

Table 3: Distribution coefficient of different stripping phase solutions.

\begin{tabular}{ll}
\hline Diluent & $\mathrm{K}_{\mathrm{D}}$ \\
\hline $\mathrm{NH}_{3}$ & 13.98 \\
$\mathrm{HNO}_{3}$ & 5.02 \\
$\mathrm{CH}_{3} \mathrm{COOH}$ & 10.36 \\
\hline
\end{tabular}

\section{CONCLUSION}

Determination of emulsion liquid membrane components for cadmium removal has been carried out. The screening components consist of carrier, diluent and stripping materials. D2EHPA and TOA as acidic and basic carrier respectively were found to have good performance for cadmium removal. In the meantime, TOA was more efficient compared to D2EHPA as it provided similar extraction efficiency even at low concentration. Among the diluents tested, kerosene was preferred as it gave better ELM performance. The sequence of extraction ability by different 
diluents as follows: kerosene $>$ n-heptane $>$ oxylene. This study also found that $\mathrm{NH}_{3}$ as the stripping agent of ELM gave the highest extraction efficiency, followed by $\mathrm{CH}_{3} \mathrm{COOH}$.

\section{ACKNOWLEDGEMENTS}

Penelitian Unggulan Perguruan Tinggi Research Grant from Ministry of Research, Technology, and Higher Education of Indonesia (084/SP2H/LT/DRPM/IV/2017) and International Collaboration Research Grant from Universitas Negeri Semarang, Indonesia (DIPA-042.01.2.400899/2017) are gratefully acknowledged.

\section{REFERENCES}

1. Ghaly, A. et al. (2014). Production, characterization and treatment of textile effluents: A critical review. Chem. Eng. Process Technol., 5(1), 1-18.

2. Othman, N. et al. (2014). Carrier assisted emulsion liquid membrane process for recovery of basic dye from wastewater using continuous extractor. $J$. Teknol., 67(2), 69-74, https://doi.org/10.11113/jt.v67.2739.

3. Hussain, J., Hussain, I. \& Arif, M. (2004). Characterization of textile wastewater. J. Ind. Poll. Contr., 20(1), 137-144.

4. Jaishree \& Khan, T. I. (2014). Monitoring of heavy metal in textile waste water of Sanganer, Jaipur (Rajasthan). Int. J. Sci. Res. Pub., 4(3), 1-4.

5. Fajri, P. Y. N. (2013). Spatial modeling for determining the location of the wastewater treatment plant of batik industry in Pekalongan, Central Java. Master diss., Institut Pertanian Bogor, Indonesia.

6. Mehta, P. (2012). Treating textile effluents by coagulation-flocculation method using different dosing compositions. Adv. Appl. Sci. Res., 3(4), 2514-2517.

7. Patel, H. \& Vashi, R. T. (2010). Treatment of textile wastewater by adsorption and coagulation. E-J. Chem., 7(4), 1468-1476, https://doi. org/10.1155/2010/987620.

8. Babaei, A. A. et al. (2017). Comparative treatment of textile wastewater by adsorption, Fenton, UV-Fenton and US-Fenton using magnetic nanoparticlesfunctionalized carbon (MNPs@c). J. Ind. Eng. Chem., 56, 163-174, https:// doi.org/10.1016/j.jiec.2017.07.009.

9. Igwegbe, C. A. et al. (2016). Adsorptive treatment of textile wastewater using activated carbon produced from mucuna pruriens seed shells. World $J$. Eng. Technol., 4, 21-37, https://doi.org/10.4236/wjet.2016.41003. 
10. Marcucci, M. et al. (2003). Membrane technologies applied to textile wastewater treatment. Ann. N. Y. Acad. Sci., 984, 53-64, https://doi. org/10.1111/j.1749-6632.2003.tb05992.x.

11. Thamaraiselvan, C. \& Noel, M. (2015). Membrane processes for dye wastewater treatment: Recent progress in fouling control. Crit. Rev. Environ. Sci. Technol., 45(10), 1007-1040, https://doi.org/10.1080/10643389.2014.9 00242.

12. El-Ashtoukhy, E. S. Z. \& Fouad, Y. O. (2015). Liquid-liquid extraction of methylene blue dye from aqueous solutions using sodium dodecylbenzenesulfonate as an extractant. Alex. Eng. J., 54(1), 77-81, https://doi.org/10.1016/j.aej.2014.11.007.

13. Muthuraman, G. \& Teng, T. T. (2009). Extraction of methyl red from industrial wastewater using xylene as an extractant. Prog. Nat. Sci., 19(10), 1215-1220, https://doi.org/10.1016/j.pnsc.2009.04.002.

14. Lin, J. et al. (2015). Toward resource recovery from textile wastewater: Dye extraction, water and base/acid regeneration using a hybrid NF-BMED process. ACS Sustain. Chem. Eng., 3(9), 1993-2001, https://doi.org/10.1021/ acssuschemeng.5b00234.

15. Kinugasa, T., Watanabe, K. \& Takeuchi, H. (1989). Effect of organic solvents on stability of liquid surfactant membranes. J. Chem. Eng. Jpn., 22(6), 593597, https://doi.org/10.1252/jcej.22.593.

16. Ding, X. \& Xie, F. (1991). Study of the swelling phenomena of liquid surfactant membranes. J. Membr. Sci., 59(2), 183-188, https://doi. org/10.1016/S0376-7388(00)81182-5.

17. Wang, Z., Jiang, Y. \& Fu, J. (1996). The entrainment swelling of emulsion during lactic acid extraction by LSMs. J. Membr. Sci., 109(1), 25-34, https:// doi.org/10.1016/0376-7388(95)00156-5.

18. Pfeiffer, R. M., Bunge, A. L. \& Navidi, W. (2003). Leakage and swell in emulsion liquid-membrane systems: Batch experiments. Sep. Sci. Technol., 38(3), 519-539, https://doi.org/10.1081/SS-120016649.

19. Djenouhat, M. et al. (2008). Ultrasonication-assisted preparation of water-inoil emulsions and application to the removal of cationic dyes from water by emulsion liquid membrane: Part 1: Membrane stability. Sep. Purif. Technol., 62(3), 636-641, https://doi.org/10.1016/j.seppur.2008.03.018.

20. Chiha, M. et al. (2010). Study on ultrasonically assisted emulsification and recovery of copper(II) from wastewater using an emulsion liquid membrane process. Ultrason. Sonochem., 17(2), 318-325, https://doi.org/10.1016/j. ultsonch.2009.09.001.

21. Cahn, R. P., Frankenfeld, J. W. \& Li, N. N. (1981). Extraction of metal ions by liquid membranes. Recent Dev. Sep. Sci., 6, 51-64. 
22. Draxler, J. \& Marr, R. (1986). Emulsion liquid membranes. Part I: Phenomenon and industrial application. Chem. Eng. Process., 20(6), 319329, https://doi.org/10.1016/0255-2701(86)80010-1.

23. Wang, K. C. (1984). Mathematical modeling of carrier mediated mass transfer through liquid membrane systems. PhD diss., New Jersey Institute of Technology, New Jersey, United States.

24. Fan, H. (1999). Chemical reactions and mass transport in emulsion liquid membrane. PhD diss., New Jersey Institute of Technology, New Jersey, United States.

25. Asrafi, F., Feyzbakhsh, A. \& Heravi, N.E. (2009). Solvent extraction of cadmium (II) from sulfate medium by bis(2-ethylhexyl) phosphoric acid in toluene. Int. J. ChemTech Res., 1, 420-425.

26. Kumar, V. et al. (2009). Solvent extraction of cadmium from sulfate solution with di-(2-ethylhexyl) phosphoric acid diluted in kerosene. Hydrometal., 96 (3), 230-234, https://doi.org/10.1016/j.hydromet.2008.10.010.

27. Thakare, Y. S., Khopkar, S. M. \& Malkhede, D. D. (2012). Highly selective liquid-liquid extraction of cadmium (II) with hexaacetato calix(6)arene. Ind. J. Chem. Technol., 19(4), 231-238.

28. Ahmad, A. L. et al. (2013). Emulsion liquid membranes for cadmium removal: Studies of extraction efficiency. Membr. Water Treat., 4(1), 15, https://doi.org/10.12989/mwt.2013.4.1.011.

29. Ahmad, A. L. et al. (2013). Emulsion liquid membrane for cadmium removal: Experimental results and model prediction. J. Teknol., 65(4), 17-24, https:// doi.org/10.11113/jt.v65.2321.

30. Basualto, C. et al. (2006). Extraction of cadmium from aqueous solutions by emulsion liquid membranes using a stirred transfer cell contactor. J. Braz. Chem. Soc., 17, 1347-1354, https://doi.org/10.1590/S010350532006000700023.

31. Pereira, L. \& Alves, M. (2012). Dyes: Environmental impact and remediation. In Malik, A. \& Grohmann, E. (Eds.). Environmental protection strategies for sustainable development. Dordrecht: Springer, 111-162, https://doi. org/10.1007/978-94-007-1591-2_4.

32. Skorovarov, J. I. et al. (1998). Solvent extraction for cleaning phosphoric acid in fertilizer production. J. Radioanal. Nucl. Chem., 229(1-2), 111A117, https://doi.org/10.1007/BF02389457.

33. Mahmoud, M. H. H. \& Mohsen, Q. (2011). Enhanced solvent extraction of cadmium and iron from phosphoric acid in chloride media. Physicochem. Prob. Min. Process., 47, 27-40.

34. Mat, H. et al. (2006). Selective emulsion liquid membrane extraction of silver from liquid photographic waste industries. Skudai: Universiti Teknologi Malaysia. 
35. Othman, N., Mat, H. \& Goto, M. (2006). Separation of silver from photographic wastes by emulsion liquid membrane system. J. Membr. Sci., 282(1-2), 171-177, https://doi.org/10.1016/j.memsci.2006.05.020.

36. Komasawa, I. \& Otake, T. (1983). The effects of diluent in the liquid-liquid extraction of copper and nickel using 2-hydroxy-5-nonylbenzophenone oxime. J. Chem. Eng. Jpn., 16(5), 377-383, https://doi.org/10.1252/ jcej.16.377.

37. Li, Y., Wang, Y. \& Dai, Y. (2004). Effect of diluents on the extraction of oxalic acid by trialkylphosphine oxide. Chin. J. Chem. Eng., 12(1), 143-148.

38. Canselier, J. P. et al. (2002). Ultrasound emulsification: An overview. J. Disper. Sci. Technol., 23(1-3), 333-349, https://doi. org/10.1080/01932690208984209.

39. Kumbasar, R. A. (2008). Transport of cadmium ions from zinc plant leach solutions through emulsion liquid membrane-containing aliquat 336 as carrier. Sep. Purif. Technol., 63(3), 592-599, https://doi.org/10.1016/j. seppur.2008.06.025.

40. Kumbasar, R.A. (2009). Extraction and concentration study of cadmium from zinc plant leach solutions by emulsion liquid membrane using trioctylamine as extractant. Hydrometal., 95(3-4), 290-296, https://doi.org/10.1016/j. hydromet.2008.07.001. 